\title{
O EFEITO FRONTEIRA DAS REGIÕES BRASILEIRAS: UMA APLICAÇÃO DO MODELO GRAVITACIONAL*
}

\author{
Sérgio Leusin Jr. ${ }^{* *}$
}

\author{
André Filipe Zago de Azevedo ${ }^{* * *}$
}

\begin{abstract}
RESUMO Este artigo analisa o efeito fronteira do Brasil e de suas regiões para o ano 1999. Esse efeito foi estimado empiricamente, utilizando-se dados de corte seccional, em um modelo gravitacional com os 26 estados brasileiros, mais o Distrito Federal e 40 países. Apesar de o Brasil ter se engajado em um processo de abertura comercial, como o ocorrido durante a década de 1990, e ter participado de Acordos Preferenciais de Comércio importantes como o Mercosul, constatou-se que o país e algumas de suas regiões apresentam elevados custos de fronteira. Os resultados encontrados indicam que o comércio entre estados brasileiros é 33 vezes superior ao comércio internacional desses estados. Para as regiões brasileiras, o efeito fronteira das regiões Norte e Nordeste é significativamente maior do que aquele observado nas regiões Sul e Sudeste.
\end{abstract}

Palavras-chave: comércio inter-regional; efeito fronteira; modelo gravitacional; integração regional

Código JEL: R12; R15; F15

\footnotetext{
* Artigo recebido em 30 de julho de 2008 e aprovado em 8 de junho de 2009.

** Mestre em Economia pela Universidade do Vale do Rio dos Sinos (Unisinos); e-mail: leusin01@ gmail.com

*** Coordenador do Mestrado em Economia da Universidade do Vale do Rio dos Sinos (Unisinos), e-mail: aazevedo@unisinos.br
} 


\section{THE BORDER EFFECT IN BRAZILIAN REGIONS:}

\section{A GRAVITY MODEL APPROACH}

ABSTRACT This paper analyzes the border effect for Brazilian goods market and its regions in 1999. This effect was quantified empirically by using cross-sectional data in a gravitational model for twenty-six Brazilian states plus the Federal District and forty other countries. Despite Brazil's involvement in commercial opening in the 90's, as well as important regional trade agreements such as Mercosul, we noticed that Brazil and some of its regions have high cross-border costs. The finding results of this equation suggest a trade 33 times higher between Brazilian states than the international trade of these states. Regarding each Brazilian region, the border effect found for intra-national trade among Northeast and North regions is significantly higher than the border effect for Southeast and Southern regions.

Key words: interregional trade; border effect; gravity model; regional integration. 


\section{INTRODUÇÃO}

A dinâmica atual da evolução do comércio internacional, favorecida pela elevada redução de custos dos meios de transportes e de comunicações, sugere que a importância das fronteiras entre os parceiros comerciais tenha diminuído significativamente. ${ }^{1}$ Além disso, o grande número de acordos comerciais atualmente em vigor, como o Nafta, Mercosul e União Europeia, fortalece os argumentos de que as fronteiras nacionais estão perdendo a importância. Ohmae (1990) apud McCallum (1995) chegou a afirmar que as fronteiras internacionais "desapareceram efetivamente". As barreiras ao comércio internacional, sejam elas oficiais, informais, tarifárias ou não tarifárias, geralmente adicionam um custo ao comércio internacional que não se observa para o comércio intranacional. O tamanho desse custo é chamado de viés doméstico de comércio, ou também efeito fronteira, sendo muito usado para mensurar de forma alternativa o grau de acesso a mercados. O efeito fronteira busca captar todos os custos de comércio relacionados exclusivamente às fronteiras entre os países. Esses custos podem ser inerentes à diferença de gostos entre as populações, que por sua vez pode ser originada pela diferença de renda per capita entre as economias, ou, ainda, por diferenças na língua e cultura, ou de política comercial.

Para medir o viés doméstico do comércio, ou efeito fronteira, a literatura tem utilizado principalmente o modelo gravitacional (por exemplo, McCallum, 1995; Helliwell, 1998; Daumal e Zignago, 2005; Silva et al., 2007). A equação gravitacional controla os fatores que determinam o fluxo bilateral de comércio, incluindo PIB e distância, além de um conjunto de variáveis econômicas, geográficas e culturais, permitindo estimar o efeito fronteira, através de uma variável dummy, que captaria o impacto adicional de comércio específico ao par de estados/países. McCallum (1995) foi o trabalho precursor a estimar o impacto das fronteiras no padrão de comércio de dois países contíguos. O autor verificou que, mesmo para países com renda semelhante e integrantes de um acordo de livre-comércio, como é o caso de EUA e Canadá, as barreiras nacionais ocasionaram um grande viés doméstico dos fluxos de comércio entre esses países. O efeito fronteira existente entre o Canadá e EUA, em 1988, revelou que o comércio entre duas províncias canadenses seria 22 vezes maior que o comércio entre uma província e 
um estado dos Estados Unidos. Silva et al. (2007), por sua vez, buscaram medir a magnitude do efeito fronteira para o Brasil. Os resultados encontrados mostraram que o comércio entre dois estados brasileiros, em 1999, era 37 vezes maior que o comércio internacional desses estados.

Dessa forma, pode-se argumentar que, mesmo ocorrendo um processo global de integração internacional, o Brasil ainda apresentaria um elevado impacto de suas fronteiras no comércio internacional. No entanto, uma questão ainda não respondida pela literatura que trata do efeito fronteira no Brasil é a magnitude do viés doméstico de comércio das cinco regiões brasileiras. A resposta para essa questão colabora com uma série de outros questionamentos. Entre eles está um de fundamental importância, que é verificar se todas as regiões possuem o mesmo grau de abertura de seus mercados e se elas souberam aproveitar na mesma intensidade o processo de abertura comercial brasileiro observado a partir da década de 1990. Este artigo tem como objetivo principal, portanto, mensurar a magnitude do efeito fronteira para as cinco regiões brasileiras para o ano 1999, último ano com informações consolidadas para o comércio interestadual no país. Este artigo está dividido, além desta introdução, em quatro seções. Na seção 2, são apresentados os resultados empíricos encontrados na literatura econômica sobre o efeito fronteira, baseados no modelo gravitacional. Na seção 3, são apresentados os dados, a abordagem econométrica e os resultados do efeito fronteira, estimados através do modelo gravitacional, para as cinco regiões brasileiras no ano 1999. A seção 4 aponta as conclusões.

\section{O EFEITO FRONTEIRA}

As mudanças ocorridas recentemente têm aproximado os países e aprofundado a integração da economia mundial. Em um período não muito distante, as barreiras ao comércio eram significativamente superiores às observadas atualmente. Essa mudança na conjuntura internacional alterou os parâmetros relacionados à política comercial e a interdependência entre os países. Dessa forma, observa-se uma maior relevância dos efeitos da economia internacional nas economias domésticas, fato ocorrido devido à maior integração econômica entre os países. 
Nesse contexto, a partir da década de 1990, começou a surgir uma série de estudos que buscaram, através do modelo gravitacional, mensurar e analisar o impacto das fronteiras sobre o padrão de comércio internacional e intranacional (por exemplo, McCallum, 1995; Wolf, 2000; Helliwell, 1998; Hidalgo e Vergolino, 1998; Nitsch, 2000; Anderson e Wincoop, 2003; Daumal e Zignago, 2005; Gil-Pareja et al., 2005; Silva et al., 2007). O efeito fronteira internacional mensura o impacto das fronteiras nacionais sobre o comércio internacional de um país, enquanto o intranacional mede o impacto das fronteiras estaduais sobre o padrão de comércio nacional e internacional de um país.

\subsection{0 efeito fronteira internacional}

Devido à sua capacidade de explicar os fluxos de comércio, o modelo gravitacional tem sido bastante utilizado para mensurar o viés doméstico dos fluxos de comércio, ou seja, medir qual é o tamanho do viés de comércio intranacional vis-à-vis ao comércio internacional, ou efeito fronteira internacional. Para tal propósito, são introduzidas dummies que assumem valor igual a 1 (um) quando o comércio é entre estados/províncias de um mesmo país e 0 (zero) quando o comércio é internacional. Dessa forma, encontra-se o coeficiente que mede o tamanho do viés de comércio entre os estados de um país comparativamente com o comércio externo. $O$ viés doméstico pode ser causado por uma série de fatores, tais como a preferência dos consumidores por produtos nacionais e a política comercial externa do país. ${ }^{2}$

O trabalho inicial deve-se a McCallum (1995), que utilizou dados de 1988 de exportações entre as províncias do Canadá e os estados dos Estados Unidos com o objetivo de comparar o comércio intranacional do Canadá com as exportações do Canadá para os Estados Unidos. Dessa forma, o autor buscou mensurar o tamanho do viés doméstico existente no Canadá, quando os fluxos de comércio entre as províncias são comparados com o comércio entre províncias e estados americanos de similar tamanho e distância. Para tanto, o autor selecionou as 10 províncias canadenses e 30 estados norte-americanos, que seriam os 20 estados mais populosos, mais todos os estados americanos que fazem divisa com o Canadá. ${ }^{3}$ Assim, sua amostra era composta de 690 observações $(90=10 \times 9$, referente ao comércio interprovíncias, mais $600=10 \times 30 \times 2$, referente ao comércio entre províncias 
do Canadá e estados americanos). ${ }^{4}$ Dessa forma, a regressão estimada pelo autor, através de Mínimos Quadrados Ordinários (MQO), foi:

$$
\operatorname{LnX} X_{i j}=\beta_{0}+\beta_{1} \operatorname{Ln} Y_{i}++\beta_{2} \operatorname{Ln} Y_{j}+\beta_{3} \operatorname{LnDIST}_{i j}+\beta_{4} D_{u m m} y_{i j}+\varepsilon_{i j}
$$

onde:

$X_{i j}$ : exportações nominais do país $i$ para o país j;

$Y_{w}:$ PIB nominal dos países $i$ e $j$;

$D I S T_{i j}$ : distância entre os países $i$ e $j$;

Dummy $_{i j}$ : assume o valor de 1 no caso de exportações intraprovíncias do Canadá e zero para exportações de províncias canadenses para estados norte-americanos;

$\beta_{0}$ até $\beta_{4}$ são parâmetros que se espera que tenham, à exceção de $\beta_{3}$, sinal positivo;

$\varepsilon_{i j}$ : erro.

Os resultados encontrados evidenciam um forte viés doméstico dos fluxos de comércio canadense. O autor observou, através do modelo gravitacional, que o comércio entre duas províncias do Canadá seria 22 vezes superior ao comércio entre províncias canadenses e estados americanos de semelhante tamanho e distância. ${ }^{5}$ A partir desse resultado se poderia afirmar que as fronteiras nacionais continuariam sendo um obstáculo importante para os fluxos de comércio internacionais. Tais resultados mostram não apenas a importância das fronteiras para o comércio, mas constituem um desafio para algumas hipóteses comumente feitas sobre a importância do comércio interestadual e internacional, tornando questionável a possibilidade do ajustamento de preços através da arbitragem internacional. ${ }^{6}$ Além disso, deve-se ressaltar que o resultado é, no mínimo, paradoxal, pois Canadá e EUA são países com culturas de consumo semelhantes, compartilham uma fronteira seca e já haviam firmado alguns acordos bilaterais de comércio entre si em 1988.

Estendendo os resultados apresentados e utilizando a mesma equação de McCallum (1995), Helliwell (1998) questiona qual o padrão de comércio de Quebec (província canadense) comparando com outras províncias do país. Os resultados, baseados em dados revisados para 1988, 1989 e 1990, em uma 
abordagem por MQO, mostram que, enquanto uma província típica comercializa 20 vezes mais com outras províncias do que com os estados americanos de semelhante tamanho e distância, para Quebec o múltiplo é ainda maior, 26 vezes. Assim, o comércio entre Quebec e EUA parece, segundo o autor e confirmando os resultados de McCallum (1995), uma alternativa menos viável do que o comércio entre Quebec e o resto do Canadá.

Anderson e Wincoop (2003), utilizando o modelo gravitacional, revisaram novamente a relação comercial entre Canadá e EUA em uma abordagem por Regressões Aparentemente Não Relacionadas (EUA - Seemingly Unrelated Regressions) e encontraram um valor diferente daqueles encontrados por McCallum (1995) e Helliwell (1998). Os autores chegaram a um valor inferior, de 16,4. Além disso, também estimaram o efeito fronteira para uma perspectiva dos EUA. O coeficiente encontrado do viés doméstico para os Estados Unidos foi significativamente inferior ao encontrado para o Canadá, de apenas 1,50. Nesse artigo, os autores inovam ao incluir uma segunda série de resultados obtidos a partir de uma equação gravitacional mais elaborada, incluindo a distância relativa ponderada pelo PIB das economias. Para essa nova equação eles adicionaram variáveis que buscavam captar o custo de oportunidade (ou resistência multilateral ao comércio) de se estar exportando de o estado “ $i$ " para o estado “ $j$ ”, assim como o custo de oportunidade de o estado " $j$ ” estar comprando de “ $i$ ”. Ou seja, quando um estado “ $i$ ” comercializa com o estado “ j”, ele está abrindo mão de comercializar com outros estados. Dessa forma, essas novas variáveis sugeridas pretendem captar esse efeito assim como atenuar as distorções ocorridas por estados isolados geograficamente ou significativamente desiguais em suas rendas.

Assim, os autores revisaram a equação de gravidade usada por McCallum (1995) e buscaram explicar as razões para os resultados obtidos. Segundo eles, dois fatores contribuíram para a obtenção de um viés doméstico tão significativo para o comércio Canadá-EUA. Primeiramente, argumentam que o padrão de comércio do Canadá com os EUA é, em grande parte, explicado pela reduzido tamanho do Canadá se comparado à economia dos EUA. Nesse contexto se inserem tanto a maior diversidade de produtos existentes nos EUA quanto as peculiaridades culturais e geográficas existentes nas principais províncias canadenses (movimentos separatistas em Quebec, isola- 
mento geográfico entre o lado leste e oeste etc.). A segunda linha de explicação para o significativo valor encontrado do viés doméstico de comércio canadense é a ausência de variáveis que expressem a resistência multilateral ao comércio nos modelos que o precederam. De qualquer forma, a partir dos estudos de McCallum (1995), Helliwell (1998) e Anderson e Wincoop (2003), pode-se dizer que a magnitude do efeito fronteira entre Canadá e EUA é bastante elevada, com as províncias canadenses comercializando entre 16 e 26 vezes mais com outras províncias do Canadá do que com estados norte-americanos de similar tamanho e distância.

Para o caso da União Europeia (UE), também se esperava a priori que o efeito fronteira seria insignificante, dado que o bloco é uma região profundamente integrada tanto doméstica como internacionalmente. Contudo, Nitsch (2000) sinalizou o contrário, ao mensurar o impacto das fronteiras nacionais no comércio internacional dos países da UE. Através do modelo gravitacional, estimado a partir de uma abordagem por Regressores Aparentemente Não Relacionados (SUR) com dados dos fluxos comerciais internacionais e intrabloco para o período compreendido entre 1979 e 1990, o autor encontrou um viés doméstico igual a 10. Isso significa dizer que, após controlar para as variáveis do modelo gravitacional, os fluxos comerciais entre os países integrantes da UE eram 10 vezes maiores que os fluxos comerciais desses países para outras nações não integrantes do bloco. Os resultados encontrados pelo autor evidenciam a importância das fronteiras regionais para blocos econômicos com elevado grau de integração econômica.

Silva et al. (2007) analisaram o efeito fronteira para o mercado brasileiro para o ano 1999, a partir dos dados da matriz de comércio interestadual obtidas de Vasconcelos (2001). O modelo utiliza variáveis como a diferença entre os PIBs per capita dos estados e países, assim como uma variável dummy que assume o valor unitário no caso da adjacência entre estados brasileiros ou países e zero caso contrário. Utilizando-se de dados de corte seccional, em um modelo gravitacional, com todos os estados brasileiros mais o Distrito Federal e 40 países, os autores encontraram um viés doméstico consideravelmente alto para os padrões observados na literatura econômica. Controlando as variáveis distância e tamanho das economias, o viés doméstico dos fluxos de comércio do Brasil mostrou-se 37,7 vezes maior do que para fora do país. Entre as justificativas para um viés dessa 
magnitude os autores citam o baixo grau de substituição entre os produtos domésticos e estrangeiros e, também, as grandes barreiras ainda existentes ao comércio internacional. Além disso, Moreira e Correa (1997) sinalizaram que fatores geográficos, como o tamanho do território e a distância em relação aos principais mercados, assim como o tamanho da população brasileira, contribuem para uma baixa internacionalização dos fluxos comerciais brasileiros. Em todas as estimativas apresentadas, tanto para Canadá, União Europeia e Brasil, nota-se ainda a importância das fronteiras nacionais para a determinação dos fluxos comerciais.

\subsection{0 efeito fronteira intranacional}

Os artigos apresentados tratam exclusivamente do efeito fronteira internacional, ou seja, avaliam o impacto das fronteiras sobre o fluxo de comércio internacional comparativamente ao comércio interestadual. Alguns trabalhos recentes, além de contemplar os resultados do efeito fronteira internacional, também incorporam o efeito fronteira intranacional, ou seja, buscam mensurar o impacto das fronteiras estaduais no padrão de comércio nacional. Wolf (2000) inovou ao mensurar o tamanho do efeito fronteira do comércio interno dos estados norte-americanos. Para tanto, o autor utilizou os dados de comércio interno dos estados (intraestadual) e do comércio entre os estados (interestadual) dos EUA para 1993, assim como dados do comércio desses estados para os países da OCDE. O propósito do autor era verificar a existência de barreiras não formais que viessem a implicar um custo adicional de comércio entre os estados norte-americanos em relação ao comércio intraestadual. A equação estimada pelo autor segue os moldes e o método sugerido por McCallum (1995) acrescida de variáveis de distância absoluta e distância relativa para os pares de países/estados, como utilizado por Anderson e Wincoop (2003). Assim, o autor introduziu uma dummy para captar o efeito fronteira intranacional, que assume valor 1 para o caso do comércio intraestadual e 0 para o caso do comércio interestadual ou internacional. Os resultados encontrados pelo autor indicam que, em média, os estados dos EUA comercializam 3,28 vezes mais consigo mesmos do que com outros estados norte-americanos.

O autor observou também que a variável adjacência desempenha um papel importante na determinação dos fluxos comerciais. De acordo com os 
resultados, os estados contíguos comercializam 2,6 vezes mais do que estados norte-americanos não adjacentes. Esse resultado é coerente com os observados na literatura internacional, mas surpreendente para o caso dos EUA. Para o autor, a importância da adjacência tende a ser alta quando o fluxo comercial necessita atravessar um terceiro estado/país. Ou seja, essa significativa relevância da adjacência para o caso norte-americano deve ser atribuída à possibilidade de existência de um fornecedor alternativo entre $\mathrm{o}$ estado importador e o exportador. O fluxo comercial entre cidades de estados não adjacentes como a Filadélfia e Nova Haven, por exemplo, tende a ser baixo devido à existência de um grande fornecedor situado entre eles, no caso a cidade de Nova York. Ao retirar a variável adjacência do modelo o autor verificou que o efeito fronteira cresce em $20 \%$, indicando que essa proporção do efeito fronteira deve ser atribuída à adjacência entre estados.

Gil-Pareja et al. (2005) analisaram o impacto do efeito fronteira na Espanha através de um modelo gravitacional com dados do comércio intranacional e internacional para o período de 1995 até 1998. Os autores buscaram estimar também o efeito fronteira para cada uma das 17 regiões espanholas. Para tanto, utilizaram informações do comércio entre as regiões, assim como o comércio internacional de cada região para 27 países da OCDE. Os resultados indicam que, após controlar para as variáveis do modelo, as regiões espanholas comercializam cerca de 22 vezes mais com outras regiões da Espanha do que com os países da OCDE. Os autores observam que o resultado para o efeito fronteira da Espanha é semelhante ao encontrado por McCallum (1995). Observaram também que o viés doméstico dos fluxos comerciais varia significativamente entre as regiões espanholas. Madri, por exemplo, ao centro do país, comercializa nove vezes mais com outras regiões espanholas do que com o exterior; já para Cantabria, no extremo norte do país, o viés doméstico é igual a 53. As ilhas Balearic apresentam o maior impacto das fronteiras sobre os fluxos de comércio (59 vezes), seguidas por Extremadura (42 vezes) e Astúrias (41 vezes). Excluindo esses resultados extremos, pode-se observar que o viés doméstico para a maioria das regiões espanholas situa-se entre 14 e 30 vezes. Os resultados apresentados pelos autores mostram que o viés doméstico, além de não ser necessariamente uniforme para regiões de um país, pode variar significativamente entre elas. Segundo os autores, esses resultados podem ser explicados pela geografia da 
Espanha, assim como pelas significativas diferenças na estrutura das firmas entre as regiões espanholas.

A inovação apresentada por Wolf (2000) fez surgir uma nova questão relacionada ao efeito fronteira, que diz respeito ao efeito fronteira intranacional. Seguindo nessa linha, Daumal e Zignago (2005) propõem-se medir o efeito fronteira internacional e intranacional para o Brasil entre os anos 1991 a 1999. Para tanto, os autores utilizam duas dummies, "home" e "Brasil”, em que a primeira capta a preferência dos estados brasileiros pelo comércio interno, ou seja, entre municípios do mesmo estado, e a segunda capta a preferência pelo comércio entre os estados brasileiros, e não com o exterior, ou seja, o efeito fronteira internacional. De forma análoga, pode-se dizer que a dummy "home" capta o impacto das fronteiras estaduais — devido a isso chamado também de efeito fronteira intranacional — e a variável dummy "Brasil" busca captar a importância da fronteira nacional para a determinação dos fluxos comerciais internacionais, ou efeito fronteira internacional. Os dados utilizados englobam os fluxos comerciais entre 26 estados brasileiros ${ }^{7}$ e os fluxos internacionais de cada estado para 164 países, para 1991, 1997, 1998 e 1999. A seguir a equação estimada em uma abordagem por efeitos fixos:

$$
\operatorname{Ln} \frac{X_{i j}}{Y_{i} Y_{j}}=\beta_{0}+\beta_{1} \operatorname{LnDIST}_{i j}+\beta_{2} \text { Home }+\beta_{3} \text { Brasil }+\beta_{4} E_{i}+\varepsilon_{i j}
$$

onde:

$X_{i j}$ : exportações do estado $i$ para o país ou estado $j$;

$Y_{w}:$ PIB nominal dos estados ou países $i$ e $j$;

$D{ } T_{i j}$ : distância do estado $i$ ao estado ou país $j$;

Home: variável dummy que assume valor 1 no caso de o comércio ser entre cidades de um mesmo estado (intraestadual) e 0 no caso de o comércio ser interestadual ou internacional;

Brasil: variável dummy que assume valor 1 caso o comércio seja entre os estados brasileiros e valor 0 em todos os outros casos;

$E_{i}$ : efeitos fixos de exportação;

$\beta_{0}$ até $\beta_{5}$ são parâmetros que se espera que tenham, à exceção de $\beta_{3}$, sinal positivo;

$$
\in_{i j}: \text { erro. }
$$


Os autores utilizam o antilogaritmo da diferença dos coeficientes das variáveis "home" e "Brasil" $[\exp ($ home-brasil) $=h b]$ para medir o grau de fragmentação interna, ou, no sentido inverso, o nível de integração doméstica. O coeficiente $h b$ captura a preferência dos estados brasileiros pelo comércio consigo mesmo e não com os demais estados do Brasil ou país estrangeiro. Assim, quanto maior é o valor de $h b$, maior é o nível de fragmentação doméstica, pois maior deverá ser a porção de comércio intraestadual da equação. Para a variável: "Brasil" a sistemática é semelhante quanto maior o seu valor, menor é a integração internacional e maior é o impacto do efeito fronteira. Dessa forma, pode-se comparar o engajamento dos estados no comércio doméstico e internacional.

Os resultados para o efeito fronteira intranacional (dummy "home") mostram que em 1999 um estado brasileiro, depois de controlados para as variáveis do modelo gravitacional, negociava 11 vezes mais com ele mesmo do que com outra unidade federativa, enquanto, em 1991, esse número chegava a 19 vezes. Ou seja, com o passar dos anos teria ocorrido uma redução da preferência comercial intraestadual em benefício do comércio interestadual no Brasil, mas ela continuaria muito elevada quando comparada à de outros países. Na tentativa de justificar esses resultados, os autores apontam alguns de seus possíveis determinantes, tais como alíquotas de tributos internos (ICMS) não uniformizadas para o comércio doméstico, diferenças culturais e na estrutura de suas economias e o padrão das compras governamentais dos estados. Para o efeito fronteira internacional (dummy "Brasil”) os resultados são surpreendentes. Em 1999, o viés doméstico dos fluxos de comércio, após controlar o tamanho das economias e a distância entre elas, é igual a 33, enquanto para o ano 1991 é de apenas $17 .{ }^{8}$ Dessa forma, os autores observam que os resultados apresentados para o Brasil contrariam os resultados esperados de acordo com a literatura econômica. Em um país como o Brasil, engajado no processo global de integração internacional, através da abertura comercial observada no decorrer da década de 1990 e a formação do Mercosul, a partir de 1991, se esperava uma queda do efeito fronteira internacional.

Apesar de os autores não terem realizado o cálculo do efeito fronteira por regiões brasileiras, pode-se deduzi-lo a partir dos coeficientes estaduais do efeito fronteira internacional. Em geral, os estados das regiões Sul e Su- 
deste apresentam os menores custos de fronteira internacional, ou seja, menores impactos do efeito fronteira para a determinação dos fluxos comerciais para o exterior. Em 1999, o intervalo de variação do coeficiente do efeito fronteira internacional dos estados do Norte vai de 6,2 até 10,3; para a região Nordeste, o intervalo é de 5,8 até 8. Para os estados do Sul e Sudeste, o intervalo de variância apresenta uma amplitude menor, com limite inferior de 1,3 e limite superior de 4. A partir dos resultados apresentados pelos autores, pode-se afirmar que os estados da região Sul e Sudeste são mais integrados internacionalmente que os das regiões Norte e Nordeste. Além disso, aqueles estados mais integrados nacionalmente também o são internacionalmente. Estados da região Norte, como Amapá e Acre, por exemplo, possuem um elevado coeficiente do efeito fronteira intranacional, assim como um alto coeficiente para o efeito fronteira internacional. Em contraposição, São Paulo, na região Sudeste, apresenta baixo coeficiente para o efeito fronteira tanto para os fluxos domésticos quanto para os internacionais. Na prática, isso significa dizer que os estados que comercializam proporcionalmente mais internamente, ou seja, com os demais estados brasileiros, também tendem a comercializar mais com o exterior.

$\mathrm{Na}$ literatura brasileira que tange a temática do efeito fronteira regional, também se destaca o trabalho de Hidalgo e Vergolino (1998). Os autores discutem o fluxo de comércio do Nordeste para o resto do Brasil e exterior usando o modelo gravitacional. No estudo, eles procuraram avaliar, para o ano 1991, a importância das fronteiras (internas e externas) sobre o padrão do comércio internacional e intranacional. Para tanto, usaram as exportações de cada estado do Nordeste para cada um dos outros 26 estados da federação e para cada um dos países com os quais os estados nordestinos mantinham comércio. A fim de conhecer melhor o papel da existência de fronteiras para o comércio exterior da região Nordeste, os autores estimaram o modelo gravitacional em uma abordagem por MQO, usando a forma log-linear. Eles constataram que o efeito da existência das fronteiras sobre os fluxos de comércio são significativos, pois as exportações interestaduais representam para o Nordeste cerca de 11 vezes mais que as exportações internacionais. Mostram também que os fluxos de comércio interno na região Nordeste são 1,75 vez maior que as exportações para as outras regiões do Brasil. A existência de fronteiras parece mostrar-se um determinante im- 
portante do comércio nordestino, principalmente a fronteira internacional. Na tentativa de justificar esses resultados os autores argumentam que a produção da região Nordeste é mais concentrada em bens primários e intermediários e o seu comércio consiste, basicamente, na troca de bens agrícolas e matérias-primas por produtos manufaturados, caracterizando um comércio interindustrial.

Os trabalhos apresentados evidenciam que as fronteiras estaduais e nacionais ainda representam um significativo custo adicional de comércio. McCallum (1995), inovou ao propor a utilização do modelo gravitacional para mensurar o impacto das fronteiras nacionais sobre o padrão de comércio de países. Wolf (2000), por sua vez, sugeriu um novo enfoque na análise do efeito fronteira utilizando o modelo gravitacional, que foi a mensuração do impacto das fronteiras estaduais no padrão de comércio de países. As proposições dos autores fizeram surgir uma vasta literatura, abordando esses novos enfoques, e os resultados apresentados nesta revisão de literatura confirmam a expectativa de que o impacto das fronteiras nacionais sobre o comércio seja maior que o impacto das fronteiras estaduais. Também se confirmou a viabilidade de se utilizar o efeito fronteira como forma alternativa para a mensuração do grau de acesso a mercados (efeito fronteira internacional), assim como para a mensuração da fragmentação doméstica (efeito fronteira intranacional). A tabela 1 apresenta uma síntese dos trabalhos apresentados nesta seção.

Tabela 1: Consolidação dos resultados e variáveis utilizadas pelo modelo gravitacional

\begin{tabular}{|c|c|c|c|c|c|c|}
\hline Autores & Período & $\begin{array}{c}\text { Região } \\
\text { Analisada }\end{array}$ & $\begin{array}{c}\text { Dimensão do } \\
\text { Efeito Fronteira }\end{array}$ & $\begin{array}{l}\mathrm{N}^{\circ} \mathrm{de} \\
\text { Obs. }\end{array}$ & Método & $\mathrm{R}^{2}$ \\
\hline McCallum (1995) & 1988 & (Canadá-EUA) & 22 & 683 & MQO & 0,8 \\
\hline Helliwell (1998) & 1988-1990 & (Canadá-EUA) & 20 & 677 & MQO & 0,8 \\
\hline Wolf (2000) & 1993 & (entre estados dos EUA) & 3,28 & 2137 & MQO & 0,8 \\
\hline $\begin{array}{l}\text { Anderson e Wincoop } \\
(2003)\end{array}$ & $\begin{array}{l}1993 \\
1993 \\
\end{array}$ & $\begin{array}{l}\text { (Canadá-EUA) } \\
\text { (EUA-Canadá) }\end{array}$ & $\begin{array}{r}16,4 \\
1,5 \\
\end{array}$ & $\begin{array}{l}589 \\
589\end{array}$ & $\begin{array}{l}\text { SUR } \\
\text { SUR }\end{array}$ & $\begin{array}{l}0,7 \\
0,8 \\
\end{array}$ \\
\hline Nitsch (2000) & 1979-1990 & (UE-mundo) & 10 & 972 & SUR & 0,9 \\
\hline $\begin{array}{l}\text { Gil-Pareja et al. } \\
(2005)\end{array}$ & 1995-1998 & $\begin{array}{l}\text { (regiões espa- } \\
\text { nholas-mundo) }\end{array}$ & 9 até 59 & 3808 & Efeitos fixos & 0,7 \\
\hline $\begin{array}{l}\text { Daumal e Zignago } \\
(2005)\end{array}$ & $\begin{array}{l}1991 \\
1999 \\
\end{array}$ & $\begin{array}{l}\text { (Brasil-mundo) } \\
\text { (Brasil-mundo) }\end{array}$ & $\begin{array}{l}17,04 \\
32,55 \\
\end{array}$ & $\begin{array}{l}2249 \\
2441 \\
\end{array}$ & $\begin{array}{l}\text { Efeitos fixos } \\
\text { Efeitos fixos }\end{array}$ & $\begin{array}{l}0,7 \\
0,7 \\
\end{array}$ \\
\hline $\begin{array}{l}\text { Hidalgo e Vergolino } \\
\text { (1998) }\end{array}$ & $\begin{array}{l}1991 \\
1991\end{array}$ & $\begin{array}{c}\text { (Nordeste-mundo) } \\
\text { (Nordeste-Brasil) }\end{array}$ & $\begin{array}{r}11,5 \\
1,75 \\
\end{array}$ & $\begin{array}{l}461 \\
461 \\
\end{array}$ & $\begin{array}{l}\text { MQO } \\
\text { MQO }\end{array}$ & $\begin{array}{l}0,6 \\
0,6 \\
\end{array}$ \\
\hline Silva et al. (2007) & 1999 & (Brasil-mundo) & 37,7 & 1334 & MQO & 0,7 \\
\hline
\end{tabular}




\section{O EFEITO FRONTEIRA PARA AS REGIÕES BRASILEIRAS}

A seção anterior apresentou uma revisão de literatura sobre o efeito fronteira, com ênfase no caso brasileiro. Notou-se a existência de um forte viés intranacional do comércio brasileiro, mesmo após o processo de abertura comercial ocorrido nos anos 1990. O trabalho de Daumal e Zignago (2005) sugere inclusive que o viés doméstico dos fluxos comerciais brasileiros teria aumentado no decorrer da década de 1990. A partir dos resultados apresentados, é possível supor que há um padrão para o efeito fronteira brasileiro para 1999, oscilando entre 32 e 37 vezes. Este capítulo busca calcular o efeito fronteira para cada uma das cinco regiões brasileiras para 1999.

\subsection{Dados}

A variável dependente são as exportações, tanto entre os 27 estados brasileiros como dos estados para os países constantes na amostra para o ano 1999. O fluxo comercial entre os estados do Brasil, também chamado de matriz de comércio interestadual, foi obtido de Vasconcelos (2001), expresso em $\mathrm{R} \$$ mil de 1999. A base de dados utilizada possui uma peculiaridade que aproxima os fluxos de comércio interestaduais computados dos fluxos de comércio interestaduais efetivamente realizados. A matriz de comércio interestadual brasileira geralmente é obtida a partir das Secretarias da Fazenda dos estados e é dividida em duas matrizes, uma com base nas entradas e outra com base nas saídas informadas pelos estados. A inovação de Vasconcelos está em confrontar os dados informados na entrada e na saída e, a partir desse confronto, considerar o maior valor absoluto informado, diminuindo assim os riscos de subestimação da matriz de comércio interestadual brasileira. Os dados da matriz de comércio interestadual foram inflacionados pelo IPCA para o ano 2000. ${ }^{9}$ Os dados do comércio de 1999 dos estados para o exterior foram obtidos do site Aliceweb, do Ministério do Desenvolvimento, Indústria e Comércio Exterior (MDIC). Para o inflacionamento dos fluxos de comércio internacionais foi usado o indicador da inflação americana ao consumidor, com ajuste sazonal. ${ }^{10}$ Com esses procedimentos passa-se a ter os fluxos de comércio internacional em dólares correntes para o ano 2000, sendo convertidos para reais pela taxa de câmbio média do ano 2000 (R $\$ /$ US $\$=1,8302)$. Dessa forma, obtém-se a matriz de comércio internacional em reais correntes para esse ano. 
Os dados do Produto Interno Bruto (PIB) e do PIB per capita dos estados brasileiros encontravam-se a preços constantes — R\$ mil de 2000, deflacionado pelo Deflator Implícito do PIB nacional, calculados pelo IBGE e obtidos no site do IPEAdata. Os dados dos demais países selecionados (PIB - US\$ - constantes de 2000 e PIB per capita) foram obtidos no banco de dados do Banco Mundial no site<http://devdata.worldbank.org>. O PIB e PIB per capita dos países da amostra encontravam-se em dólares constantes para o ano 2000, sendo necessária a conversão destes para reais de 2000 pela taxa de câmbio média anual. As distâncias, medidas em quilômetros, foram obtidas do DNIT (Departamento Nacional de Infra-estrutura de Transportes) e representam as distâncias físicas entre as capitais de cada estado. ${ }^{11}$ Para os demais países, considerou-se a distância de Brasília até a capital de cada um dos países, sendo esses dados retirados do Centre d'Etudes Prospectives et d'Informations Internationales (CEPII). Para a construção da amostra dos países importadores foram considerados alguns critérios seguidamente usados na literatura, tais como uma ampla abrangência geográfica, contemplando, no mínimo, um país para cada continente, e uma elevada participação no comércio dos estados, contendo, ao menos, $80 \%$ do total das exportações dos estados para o ano pesquisado. ${ }^{12} \mathrm{~A}$ amostra selecionada contém 40 países, contemplando ambos os critérios. As exportações para os países da amostra representam 91\% das exportações do Brasil para $1999 .{ }^{13}$

\subsection{Abordagem econométrica}

Para este estudo, o modelo a ser utilizado contempla as variáveis tradicionais anteriormente citadas, como aquelas que procuram captar os efeitos da adjacência e da similaridade da renda dos estados nos padrões de comércio entre eles. Assim, a forma da equação gravitacional aplicada ao comércio intranacional utilizada para a estimação do efeito fronteira, baseada em Silva et al. (2007), é especificada na forma log-linear e expressa como:

$$
\begin{aligned}
& \operatorname{Ln} X_{i j}=\beta_{0}+\beta_{1} \operatorname{Ln} Y_{i}+\beta_{2} \operatorname{Ln} Y_{j}+\beta_{3} \operatorname{LnDIST}_{i j}+\beta_{4} F C+\beta_{5} A_{d j} j_{i j}+\beta_{6} \operatorname{Ln} \\
& \left(P P C_{i}-P P C_{j}\right)^{2}+\varepsilon_{i j}
\end{aligned}
$$

onde:

$X_{i j}$ : exportações do estado $i$ para o estado ou país j;

$Y_{w}$ : PIB nominal dos estados ou países $i$ e $j$;

Dist $_{i j}$ : distância em km do estado $i$ ao estado ou país $j$; 
FC: uma variável dummy que assume o valor 1 se as exportações do estado $i$ vão para o estado $j$ do Brasil e 0 se elas têm como destino outro país;

Adj: uma variável "dummy" que assume o valor 1 se as exportações do estado $i$ vão para um estado ou país adjacente e 0 , caso contrário;

$P P C_{i}-P P C_{j}$ : a diferença entre o PIB per capita entre os estados e países;

$\beta_{0}$ a $\beta_{6}$ são parâmetros com sinais positivos, à exceção de $\beta_{3}$ e $\beta_{6}$;

$\varepsilon_{i j}$ : erro.

O modelo foi estimado através de MQO, contendo dados referentes ao ano 1999 dos 27 estados brasileiros e de 40 países. Em princípio havia 1.782 observações, $702(27 \times 26)$ para o comércio interestadual e 1.080 observações para o comércio internacional $(27 \times 40)$. Em 312 casos não houve registros de comércio e 70 ocorrências não se enquadraram no limite inferior estipulado (R\$ 100.000,00), logo o número de observações válidas é $1.400 .^{14}$ Essa censura na variável dependente acarretou três ganhos para o modelo; o desvio padrão de todos os coeficientes das variáveis foi minimizado, a variável $\left(P P C_{i}-P P C_{j}\right)^{2}$, que antes era significante no nível de $10 \%$, passa a ser significante no nível de $1 \%$, assim como há um ganho no coeficiente de determinação $\left(\mathrm{R}^{2}\right)$ ajustado, que passa de $62,49 \%$ para $64,75 \%$.

\subsection{Resultados do efeito fronteira para o Brasil}

Na tabela 2, são apresentadas as principais estimativas obtidas para o modelo de comércio do Brasil. Na primeira coluna, são apresentados os resultados da estimação em sua forma mais simples, excluindo as variáveis "Adj” e $\left(P P C_{i}-P P C_{j}\right)^{2}$, seguindo o padrão empregado por Silva et al. (2007). Nas colunas 2 e 3 são, respectivamente, apresentadas as estimativas da equação considerando a variável adjacência (Adj), assim como o indicador de similaridade de renda entre os estados e países $\left(P P C_{i}-P P C_{j}\right)^{2}$. Na quarta coluna, é apresentada a versão mais completa do modelo da equação gravitacional, incluindo todas as variáveis que constam da equação 10. Tradicionalmente, os modelos gravitacionais baseados em cross sections, que analisaram o efeito fronteira, apresentaram heterocedasticidade. Em virtude desse histórico o presente trabalho considera a iminência de violação das condições para que se obtenha o melhor estimador não viesado (Melnv). O teste de White confirmou a existência de heterocedasticidade e, dessa forma, o modelo foi 
Tabela 2: Estimativas do modelo gravitacional para o Brasil em 1999

\begin{tabular}{|c|c|c|c|c|c|}
\hline \multirow{2}{*}{$\begin{array}{l}\text { Variável } \\
\text { Independente }\end{array}$} & \multicolumn{5}{|c|}{ Equações } \\
\hline & (1) & (2) & (3) & (4) & (5) \\
\hline \multirow[t]{2}{*}{ Constante } & $-22,835^{\star}$ & $-23,353^{*}$ & $-23,478^{*}$ & $-23,905^{*}$ & $-28,675^{*}$ \\
\hline & $(1,11)$ & $(1,19)$ & $(1,15)$ & $(1,20)$ & $(1,50)$ \\
\hline \multirow[t]{2}{*}{$\log \left(P \mid B_{i}\right)$} & $1,037^{*}$ & $1,036^{*}$ & $1,049 *$ & $1,047^{*}$ & $1,176^{*}$ \\
\hline & $(0,03)$ & $(0,03)$ & $(0,03)$ & $(0,03)$ & $(0,04)$ \\
\hline \multirow[t]{2}{*}{$\log \left(P I B_{j}\right)$} & $0,929 *$ & $0,917^{*}$ & $0,966^{*}$ & $0,952^{*}$ & $1,023^{*}$ \\
\hline & $(0,03)$ & $(0,03)$ & $(0,03)$ & $(0,03)$ & $(0,04)$ \\
\hline \multirow[t]{2}{*}{$\log \left(D I S T_{i j}\right)$} & $-1,192^{*}$ & $-1,094^{*}$ & $-1,150 *$ & $-1,062^{*}$ & $-1,158^{*}$ \\
\hline & $(0,06)$ & $(0,07)$ & $(0,06)$ & $(0,07)$ & $(0,08)$ \\
\hline $\log \left(P P C_{i}-P P C_{j}\right)$ & & & $\begin{array}{c}-0,054^{*} \\
(0,02)\end{array}$ & $\begin{array}{c}-0,049 * \\
(0,02)\end{array}$ & $\begin{array}{r}-0,034^{*} \\
(0,02)\end{array}$ \\
\hline Dummy Adj & & $\begin{array}{l}0,617 * \\
(0,18)\end{array}$ & & $\begin{array}{l}0,572 * \\
(0,18)\end{array}$ & $\begin{array}{l}0,539 * \\
(0,16)\end{array}$ \\
\hline Dummy FC & $\begin{array}{l}3,514^{*} \\
(0,13)\end{array}$ & $\begin{array}{l}3,505^{*} \\
(0,14)\end{array}$ & $\begin{array}{l}3,515^{\star} \\
(0,13)\end{array}$ & $\begin{array}{l}3,507 * \\
(0,14)\end{array}$ & $\begin{array}{l}4,011 \text { * } \\
(0,17)\end{array}$ \\
\hline $\mathrm{R}^{2}$ Ajustado & 0,64 & 0,64 & 0,64 & 0,65 & - \\
\hline Teste $\mathrm{F}$ & 626,26 & 507,31 & 506,52 & 426,60 & - \\
\hline Num. Obs. & 1400,00 & 1400,00 & 1400,00 & 1400,00 & 1782,00 \\
\hline Método Est. & MQO & MQO & MQO & MQO & Tobit \\
\hline
\end{tabular}

corrigido pelo método de White para todas as estimações via MQO. Como em 312 casos não houve fluxo de comércio entre os estados, decidiu-se fazer uma estimação com todas as observações, pelo método Tobit, cujo resultado é apresentado na coluna $5 .^{15}$

De maneira geral, os resultados foram muito bons, com as variáveis consideradas explicando mais de $64 \%$ das variações nas exportações estaduais, e todos os parâmetros estimados são estatisticamente significantes no nível de probabilidade de $1 \%$ em todas as versões da equação gravitacional. As mudanças ocorridas nos estimadores em virtude da exclusão ou inclusão

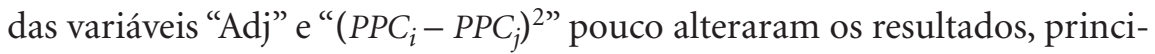
palmente no que tange aos do coeficiente do efeito fronteira. A inclusão da dummy adjacência ocasionou uma queda marginal no coeficiente da variável distância, o que era esperado e coerente com a literatura internacional. Já a inclusão da variável de similaridade de renda $\left(P P C_{i}-P P C_{j}\right)^{2}$ gerou uma elevação da significância do PIB do país/estado importador para a determinação do fluxo de comércio entre as partes. 
Os resultados mostram que a elasticidade das exportações em relação ao PIB do estado exportador se situa ligeiramente acima de 1,03 e é maior que a elasticidade das exportações em relação ao PIB do estado ou país importador, valor este que se situa em torno de 0,9 . Ou seja, os resultados parecem mostrar que o PIB do estado exportador explica em maior grau o volume de comércio entre os estados ou países. Além disso, a elasticidade do comércio bilateral com relação às rendas dos países é bastante elevada e razoavelmente estável. Em geral, um aumento de 1\% no PIB dos países implica um crescimento na mesma proporção do comércio entre eles.

A proximidade dos valores estimados para o coeficiente da variável distância reflete a robustez da estimativa. A elasticidade das exportações em relação à distância é negativa e se situa em um valor acima de 1, com elevado grau de significância estatística. O coeficiente estimado da distância absoluta demonstra sua importância como fator de resistência ao comércio: o acréscimo de $1 \%$ na distância entre um par de países acarreta uma queda um pouco superior no comércio entre eles. Os resultados são coerentes aos encontrados na literatura internacional.

A estimação do efeito adjacência no comércio está indicada na segunda e quarta colunas por coeficientes que variam de 0,57 a 0,617 . Mantendo constantes as demais variáveis, esses valores indicam que o comércio de um estado com outro adjacente é, em média, 1,7 vez maior que as exportações para aqueles estados que não têm fronteira em comum. Esse resultado é surpreendente, dada a inexistência conceitual de barreiras tarifárias, mas que encontra alguma explicação na extensão territorial do Brasil e nas dificuldades de transporte entre os estados, principalmente para os estados do Norte e Nordeste do país. ${ }^{16}$

A hipótese frequentemente usada em modelos gravitacionais, de que os estados ou países com renda per capita semelhantes tendem a comercializar mais entre si do que aqueles estados ou países com renda per capita diferentes, foi testada com a inclusão da variável $\left(P P C_{i}-P P C_{j}\right)^{2} \cdot{ }^{17}$ Observa-se que o valor encontrado para o coeficiente de similaridade da renda foi negativo, conforme esperado, e estatisticamente significativo, porém inelástico, indicando que para o Brasil a tese de Linder parece não se confirmar.

Em todas as regressões estimadas, o coeficiente da variável dummy FC, que mede o efeito fronteira do Brasil, foi significativo, com valor em torno 
de 3,5. O coeficiente encontrado para o efeito fronteira significa que, ceteris paribus, o comércio entre os estados brasileiros é cerca de 33 vezes maior do que as exportações dos estados brasileiros para o exterior. Novamente a robustez da estimativa é explicitada pela baixa variância dos valores estimados com a inclusão/exclusão de variáveis do modelo. É importante salientar a semelhança do valor encontrado para o efeito fronteira do Brasil, em 1999, com os observados na literatura. De acordo com Silva et al. (2007), o efeito fronteira do Brasil em 1999 era de 37,7 vezes. Já em Daumal e Zignago (2005), o valor encontrado do efeito fronteira do Brasil em 1999 é de 32,5 vezes. Mesmo considerando as diferenças na especificação do modelo, ambos os valores são muito próximos ao encontrado neste trabalho. ${ }^{18}$

\subsection{Resultados do efeito fronteira por regiões}

Para a estimação do efeito fronteira das regiões brasileiras, o modelo sofre alterações apenas na amostra, permanecendo o restante inalterado. O limite inferior para a variável dependente censurou 183 observações para a região Norte, 141 observações para o Nordeste e 58 observações para o CentroOeste, conforme a tabela 3. Na última coluna, consta o número de observações que foram consideradas na estimação por região. Nos estados do Sul e Sudeste, não houve fluxos inferiores a R \$ 100 mil; para o Norte, houve 183 $(40,30 \%)$ observações sem registro ou inferiores a $\mathrm{R} \$ 100$ mil, assim como $141(23,73 \%)$ observações enquadradas no mesmo critério para o Nordeste e 58 (18,93\%) para o Centro-Oeste. Dessa forma, o número de observações válidas por regiões foi o seguinte: Norte: 279, Nordeste: 453, Sudeste: 264, Sul: 198 e Centro-Oeste: 198.

Tabela 3: Considerações sobre o número de observações

\begin{tabular}{lcccc}
\hline Região & Intranacional & Internacional & $\begin{array}{c}\text { Número de Obs. } \\
\text { Censuradas* }\end{array}$ & Total \\
\hline Norte & 182 & 280 & 183 & 279 \\
\hline Nordeste & 234 & 360 & 141 & 453 \\
\hline Sudeste & 104 & 160 & 0 & 264 \\
\hline Sul & 78 & 120 & 0 & 198 \\
\hline Centro-Oeste & 104 & 160 & 58 & 206 \\
\hline Total & 702 & 1.080 & 382 & 1.400 \\
\hline * Exportações inferiores a R\$ 100 mil. & & &
\end{tabular}


O gráfico 1 apresenta o percentual do comércio intranacional no comércio total (internacional + intranacional) de cada estado brasileiro, em 1999. A percentagem média do comércio intranacional no comércio total dos estados brasileiros em 1999 é de 90,44\%, variando de 67,79\% (Pará) até 99,86\% (Distrito Federal), indicando que para os estados brasileiros o comércio doméstico corresponde a uma parcela significativa do comércio total. Os estados da região Sul, em geral, apresentam as menores participações do comércio nacional no comércio total (Rio Grande do Sul 79,69\%, Paraná 86,09\% e Santa Catarina 86,92\%), seguidos dos estados da região Sudeste (Espírito Santo 78,07\%, São Paulo 81,12\%, Minas Gerais 83,45\% e Rio de Janeiro 95,47\%). Os estados da Região Norte, Nordeste e Centro-Oeste, em geral, apresentam uma proporção mais elevada do comércio nacional no comércio total, superiores a 90\%, se comparados com as regiões Sul e Sudeste. As exceções são Pará 67,79\% (Norte), Maranhão 80,44\% (Nordeste), Bahia 87,62\% (Nordeste) e Mato Grosso 87,87\% (Centro-Oeste).

$\mathrm{Na}$ tabela 4, apresentam-se os resultados obtidos com a estimação em uma abordagem por MQO com teste White do modelo proposto para o Brasil (coluna 1), assim como para suas regiões, como pode ser observado nas colunas 2 a 6, respectivamente, Norte, Nordeste, Sudeste, Centro-Oeste e Sul. De maneira geral, os resultados foram bons, com as variáveis consideradas explicando entre 50\% e 70\% das variações nas exportações regionais. A elasticidade encontrada para as exportações em relação ao PIB do estado

Gráfico 1: Percentagem do comércio intranacional no comércio total dos estados em 1999

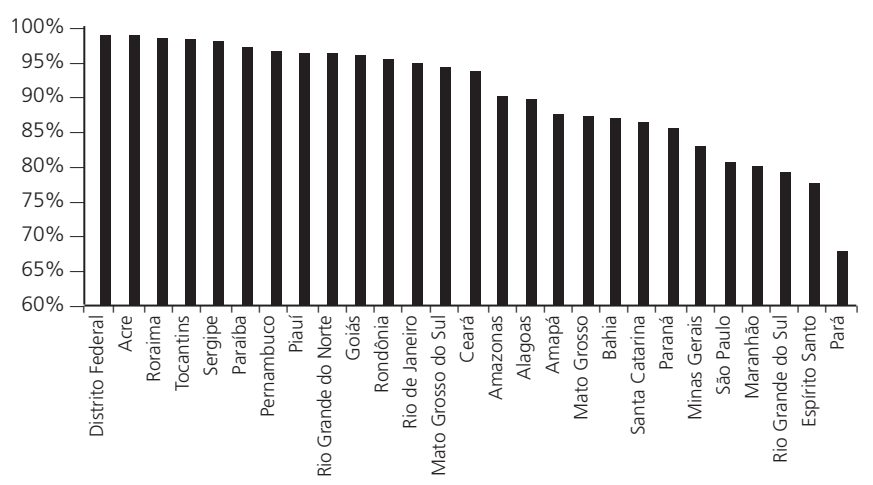

Fonte: MDIC (2008), Vasconcelos (2001). Elaboração própria. 
exportador tem valor próximo da unidade para as regiões Norte, Nordeste e Sudeste e é coerente com os resultados encontrados na literatura. Para a região Sul, os resultados parecem mostrar que o PIB do país emissor ou receptor do fluxo de comércio é menos relevante para a determinação do volume de comércio do que o observado para as outras regiões. ${ }^{19}$

Na literatura empírica que envolve o efeito fronteira, é corriqueira a observação de que a elasticidade das exportações em relação ao PIB do estado/ país exportador seja superior à elasticidade das exportações em relação ao PIB do estado/país importador. Ou seja, tradicionalmente, a renda do estado/país exportador explica em maior grau o volume exportado entre dois parceiros do que a renda do estado/país importador. Para o Brasil e para as regiões Sul e Sudeste, essa verificação também é verdadeira. Isso significa que para essas regiões o tamanho econômico do estado exportador é mais relevante para a determinação do fluxo de comércio do que o PIB do estado/ país importador. Essa dinâmica observada provavelmente deve-se ao tama-

Tabela 4: Estimativas do modelo gravitacional para Brasil e regiões 1999

\begin{tabular}{|c|c|c|c|c|c|c|}
\hline \multirow{2}{*}{$\begin{array}{l}\text { Variável } \\
\text { Independente }\end{array}$} & \multicolumn{6}{|c|}{ Equações } \\
\hline & $\begin{array}{c}(1) \\
\text { Brasil }\end{array}$ & $\begin{array}{c}(2) \\
\text { Norte }\end{array}$ & $\begin{array}{c}(3) \\
\text { Nordeste }\end{array}$ & $\begin{array}{c}\text { (4) } \\
\text { Sudeste }\end{array}$ & $\begin{array}{l}5) \\
\mathrm{C}-\mathrm{O}\end{array}$ & $\begin{array}{l}6) \\
\text { Sul }\end{array}$ \\
\hline \multirow[t]{2}{*}{ Constante } & $-23,905^{*}$ & $-24,206^{*}$ & $-23,335^{*}$ & $-21,973^{*}$ & $21,493 * * *$ & $-12,033^{* *}$ \\
\hline & $(1,197)$ & $(3,126)$ & $(2,500)$ & $(2,561)$ & $(11,168)$ & $(5,837)$ \\
\hline \multirow[t]{2}{*}{$\log \left(P I B_{i}\right)$} & $1,047^{*}$ & $0,976^{*}$ & $0,972 *$ & $1,026^{*}$ & $-0,793 * * *$ & $0,838^{*}$ \\
\hline & 0,031 & 0,089 & 0,088 & 0,078 & $(0,440)$ & 0,227 \\
\hline \multirow[t]{2}{*}{$\log \left(P I B_{j}\right)$} & $0,952 *$ & $1,013^{*}$ & $0,999 *$ & 0,961 * & $0,915^{*}$ & $0,784^{*}$ \\
\hline & 0,030 & 0,083 & 0,059 & 0,051 & 0,086 & 0,045 \\
\hline \multirow[t]{2}{*}{$\log \left(D I S T_{i j}\right)$} & $-1,062^{*}$ & $-1,069 *$ & $-1,207^{*}$ & $-1,183^{*}$ & $-1,330 *$ & $-1,169 *$ \\
\hline & $(0,067)$ & $(0,194)$ & $(0,113)$ & $(0,135)$ & $(0,211)$ & $(0,133)$ \\
\hline \multirow[t]{2}{*}{$\log$ Dif $(P P C)$} & $-0,049 *$ & $-0,034$ & $-0,020$ & $-0,058 * * *$ & $-0,002$ & $-0,062$ \\
\hline & $(0,016)$ & $(0,040)$ & $(0,036)$ & $(0,032)$ & $(0,043)$ & $(0,039)$ \\
\hline \multirow[t]{2}{*}{ Dummy Adj } & $0,572^{*}$ & 0,541 & $0,419 * *$ & 0,104 & $0,915^{*}$ & 0,540 ** \\
\hline & 0,178 & 0,391 & 0,189 & 0,253 & 0,328 & 0,272 \\
\hline \multirow[t]{2}{*}{ Dummy FC } & $3,507^{*}$ & $4,198 *$ & $4,418^{*}$ & $2,618^{*}$ & $2,958^{*}$ & $1,592^{*}$ \\
\hline & 0,136 & 0,319 & 0,197 & 0,262 & 0,412 & 0,257 \\
\hline $\mathrm{R}^{2}$ Ajustado & 0,646 & 0,513 & 0,668 & 0,717 & 0,577 & 0,671 \\
\hline Teste F & 426,60 & 499,95 & 1530,17 & 1124,89 & 477,36 & 680,71 \\
\hline Num. Obs. & 1400 & 279 & 453 & 264 & 206 & 198 \\
\hline \multicolumn{7}{|c|}{ Os valores entre parênteses são os erros padrão das estimativas. } \\
\hline \multicolumn{7}{|c|}{ * Indica significância no nível de $1 \%$. } \\
\hline \multicolumn{7}{|c|}{ ** Indica significância no nível de 5\%. } \\
\hline \multicolumn{7}{|c|}{ *** Indica significância no nível de 10\%. } \\
\hline
\end{tabular}


nho econômico em geral menor dos estados da região Norte e Nordeste, comparativamente com os da região Sul e Sudeste (Silva e Medina, 1999).

Os coeficientes estimados para a variável distância foram sempre negativos, conforme esperado, e com elevado grau de significância estatística. Para todos os casos, a variável distância é elástica e significativa no nível de significância de $1 \%$. A proximidade dos valores estimados para o coeficiente da variável distância reflete a robustez da estimativa e a forte influência negativa exercida pela distância no comércio entre os estados. A região Centro-Oeste mostrou-se mais sensível para variações na distância, com o coeficiente estimado da distância absoluta demonstrando sua importância como fator de resistência ao comércio, pois uma variação de 1\% na distância acarretaria uma diminuição de $1,33 \%$ do volume de exportações dessa região. Já a região Norte apresentou a menor sensibilidade entre as regiões, com o acréscimo de $1 \%$ na distância entre um par de países ou estados acarretando uma queda de $1,17 \%$ no comércio entre eles.

Para a variável $\left(P P C_{i}-P P C_{j}\right)^{2}$ observa-se que o valor encontrado foi negativo, como esperado, e estatisticamente significante apenas para o Brasil (1\%) e para a região Sudeste (10\%). Para todos os casos, a variável mostra-se inelástica, assim como em Silva et al. (2007). A estimação do efeito adjacência no comércio intranacional (Adj) mostra coeficientes que variam de 0,104 (Sudeste) a 0,915 (Centro-Oeste). Para as regiões Norte e Sudeste, a variável adjacência mostrou-se não significativa. Mantendo constantes as demais variáveis, esses valores indicam que o comércio de um estado com outro estado adjacente é de 1,52 (estados do Nordeste) a 2,49 (estados do Centro-Oeste) vezes maior que as exportações para aqueles estados que não têm fronteira em comum.

Algumas características ajudam no entendimento da alta significância da adjacência para a determinação dos fluxos comerciais interestaduais da região Centro-Oeste. A posição geográfica da região Centro-Oeste, distante de grandes centros econômicos, com grandes vazios populacionais e baixa atividade industrial, provavelmente colabora para a obtenção de um coeficiente tão alto para a adjacência. Os fluxos comerciais dessa região estão em sua maioria concentrados no mercado interno (ver gráfico 1), à exceção do Mato Grosso. Esse fato pode ser justificado pelo insuficiente acesso dos estados dessa região à infraestrutura destinada para o comércio exterior. Dessa forma, pode-se supor que os estados da região Centro-Oeste, deslocados 
do corredor comercial brasileiro e obrigados a enfrentar custos logísticos comparativamente mais altos que os das regiões Sul e Sudeste, por exemplo, provavelmente veem no comércio entre estados adjacentes um meio mais viável para o comércio do que para com estados não contíguos se comparado com outras regiões brasileiras.

A apresentação dos valores dos coeficientes da variável dummy para o efeito fronteira do Brasil e de suas regiões é feita mais detalhadamente na tabela 5. O coeficiente do efeito fronteira apresenta uma grande variação entre as regiões, indicando que as exportações intranacionais são entre 5 (região Sul) e 83 vezes (região Nordeste) maiores do que aquelas para os demais países. Vale notar que o efeito fronteira decresce significativamente do Norte para o Sul do país. Estados do Norte e Nordeste apresentam um efeito fronteira relativamente alto se comparado com a literatura internacional. A grande parcela do comércio intranacional no comércio total dos estados da região Norte e Nordeste, como pode ser observado no gráfico 1, parece contribuir para um viés doméstico mais elevado para essas regiões. Além disso, a malha de transportes dessas regiões mostra-se mais precária, menos diversificada e mais distante do centro econômico do país do que as das regiões Sul e Sudeste.

As regiões Centro-Oeste (20 vezes) e Sudeste (14 vezes) apresentam um viés doméstico de seus fluxos comerciais semelhante ao existente entre províncias canadenses e estados norte-americanos, como observado por McCallum (1995) -22 vezes, Helliwell (1998) -20 vezes e Anderson e Wincoop (2003) -16 vezes. A região Sul apresentou o menor viés doméstico de seus fluxos comerciais (4,9 vezes), indicando o maior grau de abertura dessa região para o exterior. A grande variação do efeito fronteira entre regiões de

Tabela 5: Efeito fronteira do Brasil e de suas regiões em 1999

\begin{tabular}{lccccc}
\hline Região & $\mathrm{FC}$ & $\begin{array}{c}\text { Desvio } \\
\text { Padrão }\end{array}$ & $\begin{array}{c}\mathrm{R}^{2} \\
\text { Ajustado }\end{array}$ & $\begin{array}{c}\text { Efeito } \\
\text { Fronteira* }\end{array}$ & $\begin{array}{c}\text { Variação do Efeito } \\
\text { Fronteira Regional } \\
\text { em Relação ao Brasil }\end{array}$ \\
\hline Brasil & 3,507 & 0,136 & 0,646 & 33,11 & - \\
\hline Nordeste & 4,418 & 0,197 & 0,668 & 82,93 & $150,5 \%$ \\
\hline Norte & 4,198 & 0,319 & 0,513 & 66,55 & $101,0 \%$ \\
\hline Centro-oeste & 2,958 & 0,412 & 0,577 & 19,25 & $-41,9 \%$ \\
\hline Sudeste & 2,618 & 0,262 & 0,717 & 13,70 & $-58,6 \%$ \\
\hline Sul & 1,592 & 0,257 & 0,671 & 4,91 & $-85,2 \%$ \\
\hline *Efeito Fronteira $=$ e $^{\text {(coeficiente da dummy do efeito fronteira). }}$ & & &
\end{tabular}


um país já foi observado na literatura internacional. Gil-Pareja et al. (2005) encontraram grande variância entre os valores do efeito fronteira das regiões espanholas, entre 9 e 59, ao passo que, para o Brasil, a variância observada foi entre 4,9 e 82,9. Os resultados mostram-se coerentes com as evidências sobre o efeito fronteira brasileiro observadas na literatura empírica.

Sá Porto (2002) sinalizou em seu estudo que as regiões Norte e Nordeste parecem ter tirado um proveito menor dos ganhos de bem-estar obtidos com o processo de integração internacional promovido pelo Mercosul no decorrer da década de $1990 .{ }^{20} \mathrm{Ou}$ seja, segundo os resultados do autor, as regiões Sul e Sudeste apresentaram impactos comparativamente mais significativos com a criação do Mercosul. O fato de o impacto da formação do Mercosul ter se mostrado mais intenso nas regiões Sul e Sudeste em parte pode ser justificado em virtude de as regiões provavelmente também apresentarem custos de fronteira menores que as regiões Norte e Nordeste durante o período de formação do Mercosul.

Os resultados aqui obtidos para os coeficientes do efeito fronteira das regiões brasileiras estão em sintonia com aqueles encontrados por Daumal e Zignago (2005) para os estados brasileiros. Os resultados daqueles autores mostram que os limites superiores e inferiores do efeito fronteira dos estados das regiões Sul (54,59 vezes para o Paraná e 22,19 vezes para o Rio Grande do Sul) e Sudeste (54,59 vezes para Minas Gerais e 3,66 vezes para São Paulo) eram significativamente inferiores ao observado para os estados das regiões Norte (297,32 vezes para o Acre e 492,74 vezes para o Pará) e Nordeste (29,80 vezes para o Piauí e 221,40 vezes para a Bahia). Essa evidência vai ao encontro dos resultados aqui apresentados, em que é nítido que as regiões Sul e Sudeste apresentam comparativamente menores custos de fronteira.

\section{CONCLUSÃO}

Neste artigo buscou-se mensurar o impacto do efeito fronteira para o Brasil e suas regiões, em 1999. O efeito fronteira busca mensurar o impacto das fronteiras sobre o padrão de comércio dos países. Com o objetivo de verificar a existência de um padrão para a magnitude do efeito fronteira, buscouse também fazer uma análise da literatura econômica que envolve o efeito fronteira. A forma usual de se estimar o efeito fronteira é através do modelo 
gravitacional, que, além das variáveis convencionais, como PIB e distância absoluta, inclui uma variável dummy associada ao comércio intranacional e/ou internacional. Essa dummy indica se o fato de o fluxo de comércio necessitar cruzar fronteiras regionais ou nacionais tem alguma influência sobre o padrão de comércio de um estado e/ou país. A conclusão principal é que as fronteiras ainda representam um significativo custo de comércio para o Brasil, especialmente para as regiões Norte e Nordeste. Observou-se que para o Brasil, em 1999, o impacto do efeito fronteira se traduz em um viés doméstico dos fluxos de comércio 33 vezes superior aos fluxos comerciais internacionais. Esse resultado mostra-se muito semelhante aos encontrados por Silva et al. (2007), que encontraram um viés de 37 vezes, assim como o resultado encontrado por Daumal e Zignago (2005), de 32 vezes. Todos esses trabalhos analisaram o efeito fronteira para o Brasil em 1999. Há uma série de justificativas para o elevado viés doméstico do comércio brasileiro, tais como o baixo grau de substituição entre produtos nacionais e estrangeiros, as elevadas barreiras ainda vigentes no comércio internacional, o tamanho do território e da população brasileira e a distância em relação aos principais mercados.

$\mathrm{Na}$ análise do efeito fronteira das regiões brasileiras observou-se que esse coeficiente apresenta uma grande variância entre as regiões, a exemplo do que já havia sido observado para as regiões da Espanha, como verificado por Gil-Pareja et al. (2005) e para os estados brasileiros por Daumal e Zignago (2005). Os valores obtidos para o efeito fronteira das regiões brasileiras indicam que o comércio interestadual é 82,93 vezes superior ao comércio internacional da região Nordeste; 66,55 vezes para a região Norte; 19,25 vezes para a região Centro-Oeste; 13,70 vezes para a região Sudeste; e 4,91 vezes para a região Sul. Em vista desses resultados, é coerente supor que, para o Brasil, a localização geográfica representa um fator determinante para a magnitude do efeito fronteira das regiões brasileiras. Pode-se concluir, também, que os resultados do efeito fronteira das regiões Norte e Nordeste são significativamente díspares dos observados nas regiões Sul e Sudeste, provavelmente por estas últimas terem tirado um proveito maior do processo de integração internacional, ocorrido principalmente no decorrer da década de 1990. Sá Porto (2002) sinalizou nesse sentido, supondo que as regiões Norte e Nordeste não obtiveram os mesmos ganhos advindos da constitui- 
ção do Mercosul se comparadas às regiões Sul e Sudeste. Outro aspecto que pode ter contribuído para a obtenção de coeficientes do efeito fronteira significativamente maiores para as regiões Norte e Nordeste em relação às regiões Sul e Sudeste é que estas últimas funcionam como uma plataforma de comércio, dada a sua estrutura industrial mais desenvolvida, concentrando as exportações do país. A própria amostra de 40 países utilizada reflete este fenômeno. Essa amostra representa 91\% das exportações totais do Brasil em 1999; contudo, as regiões Sul e Sudeste somadas representam 73,64\% da amostra, sinalizando que o padrão de comércio brasileiro corresponde, em grande parte, ao padrão de comércio das regiões Sul e Sudeste. Por fim, a péssima e pouco diversificada infraestrutura de transporte das regiões Norte e Nordeste também pode ter contribuído para a obtenção de coeficientes do efeito fronteira significativamente superiores para essas regiões.

\section{ANEXO}

Países da amostra

\begin{tabular}{llll}
\hline Estados Unidos & USA & Irã & IRN \\
\hline Argentina & ARG & Bolívia & BOL \\
\hline Holanda & NLD & Hong Kong & HKG \\
\hline Alemanha & DEU & Arábia Saudita & SAU \\
\hline Japão & JPN & Colômbia & COL \\
\hline Itália & ITA & Taiwan (Formosa) & TWN \\
\hline Bélgica & BEL & Portugal & PRT \\
\hline Reino Unido & GBR & Índia & IND \\
\hline França & FRA & Egito & EGY \\
\hline Espanha & ESP & Peru & PER \\
\hline México & MEX & Austrália & AUS \\
\hline Chile & CHL & Africa do Sul & ZAF \\
\hline Rússia & RUS & Suécia & SWE \\
\hline Paraguai & PRY & Nigéria & NGA \\
\hline Porto Rico & PRI & Indonésia & IDN \\
\hline China & CHN & Cingapura & SGP \\
\hline Uruguai & URY & Suíça & CHE \\
\hline Coreia do Sul & PRK & Turquia & TUR \\
\hline Venezuela & VEN & Noruega & NOR \\
\hline Canadá & CAN & Malásia & MYS \\
\hline
\end{tabular}




\section{NOTAS}

1. Para uma compreensão do processo de redução de custos dos meios de transporte e comunicação observados no mundo moderno, ver Baldwin e Martin (1999).

2. Esse coeficiente também pode ser interpretado como uma mensuração alternativa do grau de acesso a mercados, ou seja, mede o quanto os custos de comércio associados às fronteiras interferem nos fluxos de comércio internacionais.

3. Segundo o autor, a amostra dos estados americanos (30 estados) correspondia a $90 \%$ do comércio do Canadá com os EUA no período examinado.

4. Em sete casos não havia registro de comércio, deixando a amostra final com 683 observações.

5. Como a equação é estimada em logs, o coeficiente associado a qualquer variável dummy é: [ $\exp ($ coeficiente da dummy)], enquanto o percentual equivalente é: [(exp(coeficiente da dummy) -1$) \times 100]$.

6. A argumentação da possibilidade da não ocorrência da arbitragem de preços é um dos seis enigmas da economia internacional observados por Obstfeld e Rogoff (2000).

7. Os autores não consideraram Tocantins para a estimação do efeito fronteira.

8. Ou seja, para 1999 os fluxos de comércio doméstico eram 33 vezes superiores aos fluxos de comércio internacionais, e para 1991 o mesmo índice era de apenas 17 vezes.

9. Os dados terão como base o ano 2000, pois o PIB para os países e para os estados brasileiros encontrava-se nesse padrão.

10. Conhecida sob a denominação CPI - All Items, com ajuste sazonal $(1982-84=100)$.

11. A distância entre duas cidades é medida de centro a centro e os caminhos são os mais curtos, dando preferência às rodovias asfaltadas (DNIT, 2007). As distâncias dos estados de Piauí e Amapá, indisponíveis no DNIT, foram coletadas no site $<$ http://www.guialog. com.br>.

12. Ver McCallum (1995) e Sá Porto (2002).

13. A lista completa dos países está anexa.

14. Devido ao fato de as regiões Sul e Sudeste não apresentarem fluxos inferiores a R\$100 mil e representarem 73,64\% dos fluxos comerciais totais do Brasil em 1999, utilizou-se esse valor como padrão (limite inferior) dessas regiões para as regiões Norte, Nordeste e Centro-Oeste.

15. A estimação através do método Tobit trata diretamente dos dados da amostra censurada para a variável endógena. Esse procedimento incorpora implicitamente informação nas observações iguais a zero, com as observações positivas sendo utilizadas para estimar o valor do comércio, dado que ele é positivo, enquanto as observações iguais a zero são usadas para estimar a probabilidade de o comércio ser positivo.

16. Na prática as diferentes alíquotas do ICMS (Imposto sobre Circulação de Mercadorias e Serviços) existentes entre os estados brasileiros acabam por criar um tipo alternativo de barreira tarifária. 
17. Tradicionalmente, muitas teorias do comércio internacional enfatizam a ótica da oferta para explicar o padrão do comércio internacional. As hipóteses de Linder (1961) implicam que o padrão de comércio bilateral é determinado pela similaridade de renda entre os países. Ou seja, países de renda alta tenderiam a comercializar com países de renda semelhante e países de renda baixa apresentariam uma propensão maior de comercializar com países de renda baixa. Resumidamente, pode-se dizer que as hipóteses de Linder são as que seguem: a demanda é um importante determinante do comércio; a demanda doméstica determina qual a variedade de produtos que o país irá produzir; e a variedade de produtos produzidos por um país será exportada principalmente para países com demanda similar.

18. Um fator que pode ter colaborado para a obtenção de coeficientes do efeito fronteira bastante semelhantes é a base de dados comum da matriz de comércio interestadual.

19. Para o Centro-Oeste, o sinal foi contrário ao esperado $(-0,79)$.

20. Em relação ao Mercosul, uma série de trabalhos buscou estimar os efeitos do bloco sobre os fluxos de comércio intra e extrabloco (por exemplo, Kume e Piani, 2000; Sá Porto, 2002; Azevedo, 2004).

\section{REFERÊNCIAS BIBLIOGRÁFICAS}

ANDERSON, J.; WINCOOP, E. Gravity with gravitas: a solution to the border puzzle. The American Economic Review, v. 93, p. 170-192, 2003.

AZEVEDO, A. O efeito do Mercosul sobre o comércio: uma análise com o Modelo Gravitacional. Pesquisa e Planejamento Econômico, v. 34, p. 307-339, 2004.

BALDWIN, R.; MARTIN, P. Two waves of globalization: superficial similarities, fundamental differences. National Bureau of Economic Research. Working Paper 6904, 1:30. 1999. Disponível em: http://www.nber.org/papers/w6904.pdf

CENTRE D'ETUDES PROSPECTIVES ET D'INFORMATIONS INTERNATIONALES (CEPII), Disponível em: http://www.cepii.fr/anglaisgraph/news/accueilengl.html, acessado em $16 / 12 / 2007$.

DAUMAL, M.; ZIGNAGO, S. The border effects in Brazil. 2005. Disponível em: http://www. dauphine.fr/globalisation/daumal2.pdf Acessado em 15/12/2007.

DNIT. http://www1.dnit.gov.br/rodovias/distancias/distancias.asp. Acessado em 23/12/2007.

GIL-PAREJA S.; LLOREA-VIVEIRO R.; MARTINEZ-SERRANO J.; OLIVER-ALONSO J. The border effect in Spain. The World Economy, v. 28, p. 1617-31, 2005.

HELLIWELL, J. How much do national borders matter? Washington D. C.: Brookings Institution Press, 1998, v. 156.

HIDALGO, A.; VERGOLINO, J. O nordeste no comércio inter-regional e internacional: um teste dos impactos por meio do modelo gravitacional. Economia Aplicada, v. 2, p. 707-725, 1998. 
KUME, H.; PIANI, G. Fluxos bilaterais de comércio e blocos regionais: uma aplicação do modelo gravitacional. Pesquisa e Planejamento Econômico, v. 30, p. 1-21, 2000.

LINDER, S. An Essay on Trade and Transformation. Nova York: John Wiley, 1961.

MCCALLUM, J. National borders matter: Canada-US regional trade patterns. American Economic Review, v. 85, p. 615-623, 1995.

MDIC- Ministério do Desenvolvimento, Indústria e Comércio Exterior, 2008.

MOREIRA, M.; CORREA, P. Abertura comercial e indústria: o que se pode esperar e o que se vem obtendo. Revista de Economia Política, São Paulo, v. 17, p. 61-91, 1997.

NITSCH, V. National borders and international trade: evidence from the European Union. Canadian Journal of Economics, v. 33, p. 1091-1105, 2000.

OBSTFELD M.; ROGOFF K. The six major puzzles in International Macroeconomics: is there a common cause? NBER Working Paper, 7777, 2000. http://nber15.nber.org/papers/ w7777

SÁ PORTO, P. Mercosul and regional development in Brazil: a gravity model approach. Revista Estudos Econômicos, v. 32, p. 125-153, 2002.

SILVA, B.; MEDINA, M. Produto Interno Bruto por unidades da federação 1985-1998. Texto para Discussão, Rio de Janeiro: IPEA, n. 677, 1999.

SILVA, O.; ALMEIDA, F.; OLIVEIRA, B. Comércio internacional “ $x$ ” intranacional no Brasil: medindo o efeito-fronteira. Nova Economia, v. 17, p. 427-439, 2007.

VASCONCELOS, J. Matriz de fluxo do comércio interestadual no Brasil - 1999. Texto para Discussão, Rio de Janeiro: IPEA, n. 817, ago. 2001.

WOLF H. Intranational Home Bias in Trade. The Review of Economics and Statistics, v. 82, p. $555-563,2000$. 